\title{
Hyperoxic Ventilated Premature Baboons Have Increased p53, Oxidant DNA Damage and Decreased VEGF Expression
}

\author{
WILLIAM M. MANISCALCO, RICHARD H. WATKINS, JASON M. ROPER, RHONDA STAVERSKY, \\ AND MICHAEL A. O'REILLY \\ Division of Neonatology, Strong Children's Research Center, Pulmonary Biology and Disease Program, \\ Department of Pediatrics, University of Rochester School of Medicine, Rochester, NY, 14642
}

\begin{abstract}
Hyperoxia is implicated in the pathogenesis of bronchopulmonary dysplasia (BPD), a chronic lung disease of premature infants. High levels of supplemental oxygen can result in microvascular endothelial cell death and may disrupt lung development. In postnatal animals, hyperoxia inhibits expression of vascular endothelial growth factor (VEGF), which is required for normal vascular development. A potential mechanism of oxygen effects on VEGF is induction of p53, a transcription factor that represses VEGF gene transcription. Oxidant DNA damage can increase $\mathrm{p} 53$. We used a moderately premature baboon model of hyperoxia to examine p53, oxidant DNA damage, and VEGF expression. Fetal baboons delivered at $140 \mathrm{~d}$ of gestation (75\% of term) were ventilated with $100 \%$ oxygen or oxygen as needed for 6 or 10 d. Lungs from the 10-d 100\% oxygen animals had increased nuclear p53, compared with the oxygen as needed animals. The mechanism of increased p53 was probably related to oxidant DNA damage, which was documented by increased oxidized guanine. Dual fluorescent confocal microscopy found
\end{abstract}

\section{ABSTRACT}

increased oxidized guanine in mitochondrial DNA of distal lung epithelial cells. Distal epithelial cell VEGF expression was decreased and p21, another downstream target of p53, was increased in the distal epithelium of the hyperoxic animals. These data show that $\mathrm{p} 53$ is induced in hyperoxic fetal lung epithelium and are consistent with p53 repression of VEGF expression in these cells. The findings suggest that oxidant DNA damage may be a mechanism of increased p53 in hyperoxic fetal lung. (Pediatr Res 58: 549-556, 2005)

$\quad$ Abbreviations
8-oxoG, 8-hydroxy-2'-deoxyguanosine
ARDS, acute respiratory distress syndrome
BPD, bronchopulmonary dysplasia
HIF-1, hypoxia inducible factor-1
RPA, ribonuclease protection assay
VEGF, vascular endothelial growth factor
VEGFR1, vascular endothelial growth factor receptor-1

In postnatal lung, hyperoxia has diverse deleterious effects, including decreased expression of lung VEGF (6-8). Pulmonary VEGF was decreased in various clinical lung injuries in which oxygen therapy was used, including ARDS, sepsis, and BPD $(3,9,10)$. VEGF has multiple roles in vascular development and maintenance and is essential for formation of the embryonic vasculature, as demonstrated by embryo lethality of VEGF heterozygous null mutants (11). In fetal lung in the late canalicular stage, VEGF was expressed mainly by distal airspace epithelial cells and its expression increased during lung development $(5,12,13)$. Absence of key VEGF isoforms, which are the products of alternative mRNA splicing, resulted in impaired fetal lung microvascular development (14). Withdrawal of VEGF resulted in endothelial cell death, suggesting that VEGF may also be a survival factor for endothelial cells $(15,16)$. The mechanisms of decreased VEGF expression in hyperoxia are not known, but VEGF is strongly induced by HIF-1, a transcription factor that is expressed in hypoxic conditions (17).
Received September 28, 2004; accepted January 26, 2005.

Correspondence: William Maniscalco, M.D., Box 651, Department of Pediatrics, University of Rochester Medical Center, 601 Elmwood Avenue, Rochester, NY 14642: e-mail: William_Maniscalco@URMC.Rochester.edu

This work was supported by NHLBI grants HL63400 (W.M.M.) and HL67392 (M.A.O.).

DOI: 10.1203/01.pdr.0000176923.79584.f7 
Hyperoxic damage to cells results from reactive oxygen species (ROS) interaction with macromolecules such as DNA, lipids and proteins. For DNA, the damage consists of strand breaks, base modifications, sister chromatid exchanges and oxidation of guanine to 8-oxoG. Detecting DNA with 8-oxoG can identify cells with oxidant DNA damage (18-20). Oxidized guanine is found in damaged DNA in both nuclei and mitochondria (21). Oxidant injury of tissues may be exacerbated by impaired VEGF signaling. VEGF induces MnSOD and nitric oxide, which are both involved in scavenging ROS $(22,23)$.

A potential mechanism that may regulate VEGF expression in hyperoxic lung injury is increased $\mathrm{p} 53$, which can be induced by DNA damage. A multifunctional transcription factor, p53 is increased in hyperoxic injury of adult murine lung (24). Multiple lung cell types, including alveolar epithelial cells, express p53 in vivo after hyperoxia. VEGF transcription is decreased by p53 in vitro and in vivo (25-28). The mechanism of p53 inhibition of VEGF expression involves HIF-1 and $\mathrm{Sp}-1$, transcription factors that regulate VEGF gene transcription $(25,29)$. Very little is known about p53 in lung development, but it may be related to differentiation of the normal alveolar epithelium (30). In oxidant lung injury, p53 may inhibit cell proliferation by induction of $\mathrm{p} 21^{\mathrm{CIP} 1 / \mathrm{WAF} 1}$ (hereafter p21) to allow repair of DNA damage (31). Expression of p53 is also characteristic of endothelial cells that are apoptotic $(32,33)$. Although lung p53 is induced in adult rodent hyperoxic injury, it is not known whether p53 is induced in hyperoxic injury of developing lung. The cell-specific correlation of p53 with VEGF expression or oxidant DNA damage is also not known.

To investigate the effects of hyperoxia on p53, oxidant DNA damage and VEGF expression, we used a well-described model of moderately premature baboons delivered at $140 \mathrm{~d}$ of gestation ( $75 \%$ of term) that were treated with ventilation and either $100 \%$ oxygen or oxygen as needed (PRN oxygen) for up to $10 \mathrm{~d}$. Baboons treated with $100 \%$ oxygen are known to have decreased endothelial cells (34). We hypothesized that ventilation of these animals with $100 \%$ oxygen would result in oxidant DNA damage, increased p53, and decreased VEGF expression.

\section{MATERIALS AND METHODS}

Animals and hyperoxia exposure. The Southwest Foundation for Biomedical Research (San Antonio, TX) provided baboon lung samples. All animal procedures were reviewed and approved by the Animal Association for Accreditation of Laboratory Animal Care guidelines. Gestational controls were delivered by hysterotomy at $140 \pm 2 \mathrm{~d}, 146 \pm 2 \mathrm{~d}$ and $160 \pm 2 \mathrm{~d}$ gestation. Some baboons delivered at $140 \pm 2 \mathrm{~d}$ were treated with standardized protocols as detailed previously $(35,36)$. These animals were intubated, placed on a ventilator and treated with either PRN (pro re nada) oxygen to maintain $\mathrm{PO}_{2}$ between 50 and $80 \mathrm{~mm} \mathrm{Hg}$ or $100 \%$ oxygen continuously. In both groups, mechanical ventilation was adjusted to maintain $\mathrm{PCO}_{2}$ between 35 and $55 \mathrm{~mm}$ $\mathrm{Hg}$. Surfactant replacement was not administered. The animals were killed at $6 \mathrm{~d}$ and $10 \mathrm{~d}$. In the PRN group, the mean $\mathrm{FIO}_{2}$ was $\sim 0.60$ for the first $48 \mathrm{~h}$ and then declined to $\sim 0.23$ by $80 \mathrm{~h}$ of age. The $\mathrm{FIO}_{2}$ remained at this level for the remaining study time. At necropsy the lungs were inflation fixed by instillation of $4 \%$ paraformaldehyde in $0.1 \mathrm{~mol} / \mathrm{L}$ phosphate buffer at $20 \mathrm{~cm}$ $\mathrm{H}_{2} \mathrm{O}$ and tissue blocks were embedded in paraffin and sectioned.

Immunohistochemistry and confocal microscopy. Primary antibodies used were mouse monoclonal anti-human p53 (Ab-6, clone DO-1, Oncogene Research Products, San Diego, CA), Alexa-594 conjugated mouse monoclonal anti-cytochrome oxidase subunit 1 antibody (clone 1D6, Molecular Probes, Eugene, OR) and mouse monoclonal anti-human p21 antibody (clone SX-118, B. D. PharMingen, San Diego, CA). The anti-p53 DO-1 clone reacts with total p53. The secondary antibody was biotinylated horse anti-mouse IgG (Vector Labs, Burlingame, CA). Control antibodies were nonimmune monoclonal mouse $\mathrm{IgG}$.

After removal of paraffin, the lung sections were rehydrated through graded ethanol washes and rinsed in deionized water. Antigen retrieval was performed by heating the slides in $50 \mathrm{mmol} / \mathrm{L}$ Tris $\mathrm{pH} 10$ for $15 \mathrm{~min}$, followed by cooling at $25^{\circ} \mathrm{C}$ for $20 \mathrm{~min}$. Slides were treated with $1 \%$ hydrogen peroxide in methanol and rinsed in water. Slides were rinsed in $50 \mathrm{mmol} / \mathrm{L}$ Tris 150 $\mathrm{mmol} / \mathrm{L} \mathrm{NaCl} \mathrm{pH7.5} \mathrm{(TBS)} \mathrm{and} \mathrm{then} \mathrm{blocked} \mathrm{with} \mathrm{3 \%} \mathrm{horse} \mathrm{serum} \mathrm{in} \mathrm{TBST}$ (TBS $+0.05 \%$ Tween 20). Slides were incubated for $3 \mathrm{~h}$ in anti-p53 antibody or anti-p21 antibody (1:50 in TBS $+2 \%$ horse serum), rinsed in TBS, incubated $45 \mathrm{~min}$ with biotinylated horse anti-mouse $\operatorname{IgG}(1: 200)$, rinsed, treated for 30 min with Vectastain $\mathrm{ABC}$ Elite, rinsed, and stained with $\mathrm{DAB}$ substrate (Vector Labs).

Staining for 8-oxoG was performed using an OxyDNA assay kit (Calbiochem, San Diego, CA). Briefly, sections were deparaffinized and rehydrated through graded ethanols before subjecting to antigen retrieval by simmering in $50 \mathrm{mmol} / \mathrm{L}$ Tris $\mathrm{pH} 9.5$ for $10 \mathrm{~min}$. Sections were permeabilized with methanol at $-20^{\circ} \mathrm{C}$, blocked and incubated overnight with FITC-conjugated 8-oxoG binding protein at $4^{\circ} \mathrm{C}$. Sections were washed extensively, immersed in DAPI, and visualized with a Nikon E800 fluorescence microscope. Images were captured with a SPOT-RT digital camera. When co-staining for mitochondria, sections were co-incubated overnight with 8-oxoG and Alexa-594 conjugated mouse anti-cytochrome oxidase subunit 1 antibody. These sections were not treated with DAPI but were scanned with a Leica TCS SP Spectral Confocal microscope, equipped with an upright DMRXE.

Western immunoblot. Frozen lung tissue was homogenized and the proteins $(50 \mu \mathrm{g})$ were separated by SDS-PAGE and transferred to polyvinylpyrrolidone fluoride membrane as described (5). The membranes were blocked for $1 \mathrm{~h}$ at room temperature in phosphate-buffered saline (PBS) containing 5\% nonfat dry milk plus $0.05 \%$ Tween 20 (PBST). The membranes were then incubated overnight at $4^{\circ} \mathrm{C}$ in primary anti-p53 antibody (1:1000, Oncogene Research Products, Cambridge, MA) followed by three washes in PBS to remove nonspecific interactions. Membranes were then incubated in secondary antibody (goat anti-mouse; Southern Biotechnology, Birmingham, AL) for $1 \mathrm{~h}$ at room temperature. After washing the membranes with PBST, specific antibody interactions were visualized by chemiluminescence (Amersham, Arlington Heights, IL). As a loading control, membranes were also blotted for $\beta$-actin (1:5000; Sigma Chemical Co., St. Louis, MO). The data are expressed as the ratio of $\mathrm{p} 53$ to $\beta$-actin.

In situ hybridization. Cell-specific location of VEGF mRNA was conducted as detailed previously $(5,6)$. The VEGF cDNA is $94 \%$ homologous to human VEGF and hybridizes to all VEGF mRNA splice variants. Briefly, lung tissue sections on TES-treated slides were treated with proteinase $\mathrm{K}$ and equilibrated in triethanolamine ( $\mathrm{pH}$ 8.0) and acetic anhydride. Prehybridization was at $55^{\circ} \mathrm{C}$ for $2 \mathrm{~h}$. Hybridization was performed at $53^{\circ} \mathrm{C}$ using ${ }^{33} \mathrm{P}$-labeled sense or anti-sense probes. After hybridization, the slides were rinsed and digested with RNases, and stringent washes were performed in $0.1 \times$ salinesodium citrate (SSC) at $64^{\circ} \mathrm{C}$. The slides were dipped in NTB-2 emulsion and exposed at $4^{\circ} \mathrm{C}$.

Ribonuclease protection assay. These assays were performed as described previously (5). Briefly, lung tissues were lysed in $4 \mathrm{~mol} / \mathrm{L}$ guanidinium isothiocyanate, $0.5 \% \mathrm{~N}$-lauryl sarcosine, and $25 \mathrm{mmol} / \mathrm{L}$ sodium citrate, and stored at $-80^{\circ} \mathrm{C}$. Total cell RNA was extracted by standard methods. The ribonuclease protection assays were performed with commercial reagents and protocols (Riboquant; PharMingen). Radiolabeled, single-strand RNA probes for VEGF, VEGFR-1, and L32 were synthesized using T7 polymerase. RNA samples, including human RNA and yeast transfer RNA $(2 \mu \mathrm{g})$ as positive and negative controls, were dried and resuspended in hybridization buffer and radiolabeled probe. The samples were denatured at $90^{\circ} \mathrm{C}$ and incubated overnight at $56^{\circ} \mathrm{C}$. Single-stranded RNA was digested in Rnase A/T1 followed by proteinase $\mathrm{K}$ digestion. The remaining radiolabeled RNA fragments were resolved on a $6 \%$ acrylamide/urea gel, using radiolabeled probe as size markers. The gels were dried and quantified by phosphorimaging. Data for VEGF and VEGFR-1 are expressed relative to L32, a ribosomal protein.

VEGF mRNA splice variant analysis. VEGF mRNA splice variants were analyzed by reverse transcriptase polymerase chain reaction as described previously $(5,37)$. Briefly, primers located in VEGF exons 5 and 8 were used to amplify the splice variants $\left(\mathrm{VEGF}_{189}, \mathrm{VEGF}_{165}\right.$, and $\left.\mathrm{VEGF}_{121}\right)$ in the presence of $\left[{ }^{32} \mathrm{P}\right] \mathrm{dCTP}$. Amplified products were separated on highly denaturing polyacrylamide gels and quantified by phosphorimaging and image analysis. To account for differences in signal intensity due to the differences in splice variant sizes, the data are expressed as molar ratios. 


\section{RESULTS}

Hyperoxic injury increases lung p53 expression. Lungs from gestational controls and animals treated with PRN oxygen or $100 \%$ oxygen for 6 and $10 \mathrm{~d}$ were immunostained with antibody against total p53 (Fig. 1). Gestational controls at 140 and $146 \mathrm{~d}$ had occasional cell nuclei that stained for p53 (Fig. $1 \mathrm{~A}$ and $\mathrm{B})$. Compared with the gestational controls, the 6-d PRN oxygen animals had increased staining of nuclei that were mainly in thickened inter-airspace septa (Fig. 1C, arrow). By contrast, the animals treated with 100\% oxygen for $6 \mathrm{~d}$ had substantially increased nuclei that stained for p53 (Fig. 1D, arrow). A similar increase in p53-positive nuclei was noted in the 10-d 100\% oxygen animals compared with the 10d PRN oxygen group (Fig. 1E and F). Very little cytoplasmic staining was noted. In both $100 \%$ oxygen-treated groups, a broad range of cell types had nuclei that contained p53, including distal airspace epithelial cells and mesenchymal cells in the interairspace septa. With these methods we could not identify the specific mesenchymal cells that had increased p53. Macrophages in the alveolar spaces often had p53-stained nuclei (arrowheads, Fig. 1D). Sections incubated with control antibody had minimal staining (Fig. 1D, insert).

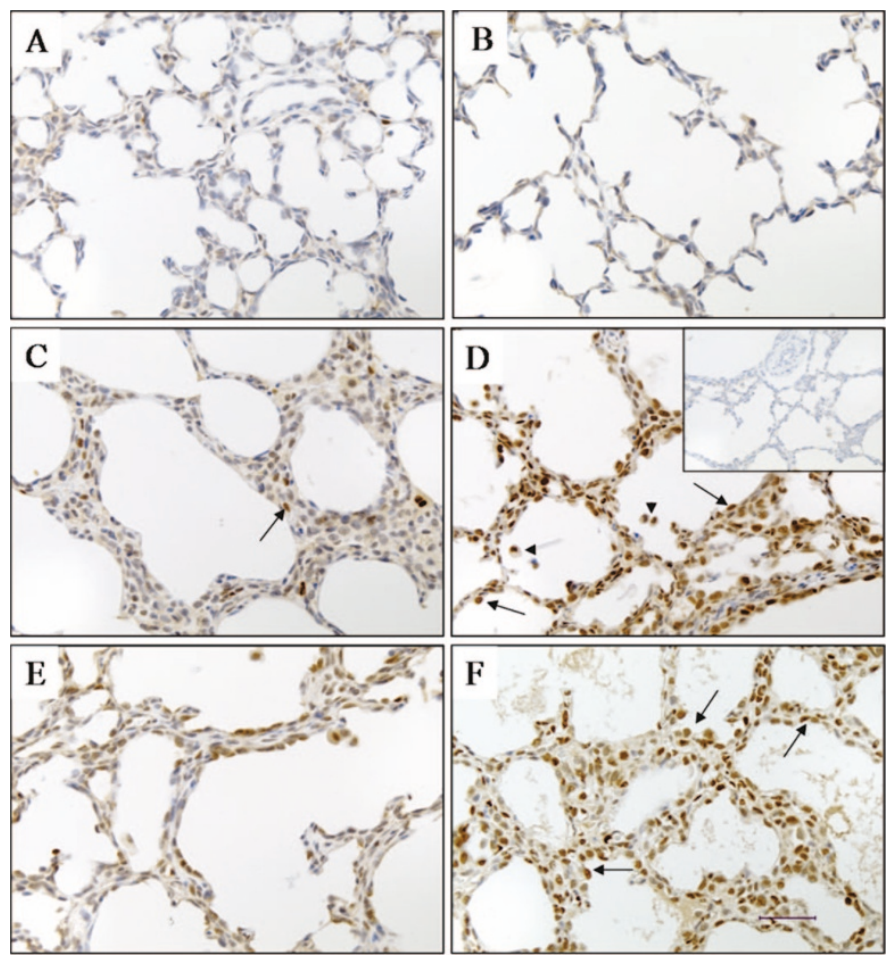

Figure 1. Immunohistochemistry for p53 in hyperoxic fetal baboon lung: 140-d gestational control $(A)$ and 146-d gestational control $(B)$ have few p53-positive (brown stained) nuclei. $C$ : Animal delivered at $140 \mathrm{~d}$ of gestation and treated with ventilation and PRN oxygen for $6 \mathrm{~d}$. Arrow indicates brown-stained nucleus containing p53. $D$ : Animal treated with ventilation and $100 \%$ oxygen for $6 \mathrm{~d}$. Arrows shows epithelial cells with p53-positive nuclei. Arrowheads indicate macrophage with p53. Insert shows minimal staining with control antibody. E: Animal treated with ventilation and PRN oxygen for $10 \mathrm{~d}$. $F$ : Animal delivered at $140 \mathrm{~d}$ and treated with ventilation and $100 \%$ oxygen for $10 \mathrm{~d}$. Arrows indicate p53-positive nuclei in epithelial cells. All sections were stained simultaneously using identical conditions. Representative sections from three animals from each group. Bar $=50 \mu \mathrm{M}$.
Increased 53 protein in hyperoxic lung. Western immunoblotting for total p53 (Fig. 2A and B) showed relatively little expression of the protein in the 140-d gestational controls and the 6-d PRN oxygen animals. The 6-d 100\% oxygen animals had increased p53 protein, but the quantification did not reach statistical significance. Compared with the 10-d PRN animals, however, the 10-d 100\% oxygen animals had a significant increase in $\mathrm{p} 53$ protein relative to actin $(p=0.02)$, confirming the qualitative findings on immunohistochemistry. At higher concentrations, p53 protein ran as a doublet (Fig. 2A), which might be due to proteolytic processing of the native protein. The antibody used for this analysis detects total p53. It has been widely used by us and others (24) and identified no significant nonspecific bands on Western analysis.

Increased 8-oxoG in hyperoxic lung. Increased expression of p53 may result from oxidant DNA damage, which can be detected by identification of 8-oxoG, an oxidation product of guanine. We used a fluorescent peptide that binds specifically to 8-oxoG in both nuclear and mitochondrial DNA. Very little binding of 8-oxoG, noted as green (FITC) signal, was found in gestational control lungs (Fig. 3A and B), suggesting minimal nonspecific binding of the peptide. In the 140-d 6-d PRN oxygen lungs, fine speckles of green are noted in scattered parenchymal cells (Fig. 3C). The 140-d 6-d 100\% oxygen lungs (Fig. 3D) had increased 8-oxoG signal in parenchymal cells (arrows), including distal epithelial and mesenchymal

A.

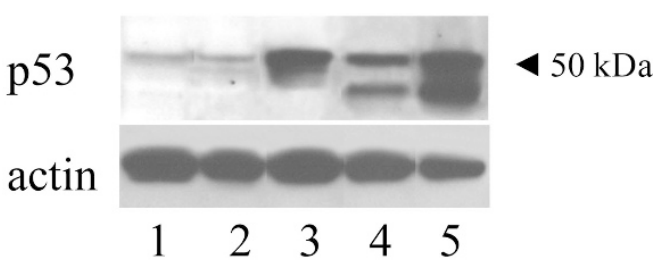

B.

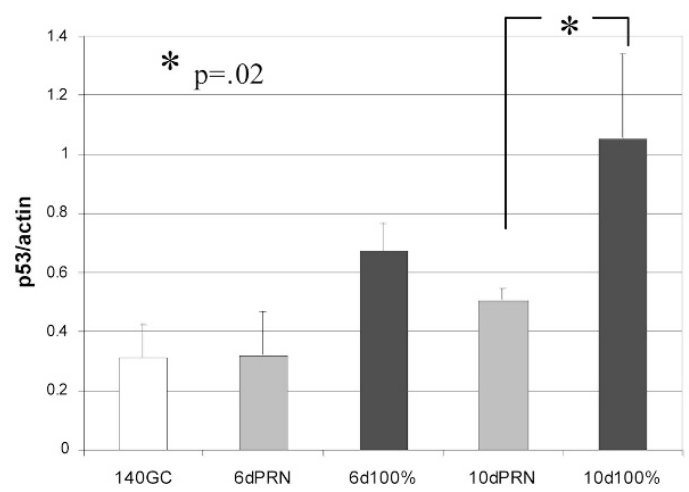

Figure 2. Western immunoblot for $\mathrm{p} 53$ in hyperoxic fetal baboon lung. $A$ : Representative immunoblot for p53 and actin. Each lane contained $50 \mu \mathrm{g}$ of total lung protein. Lanes are 1: 140-d gestational control; 2: 6-d PRN oxygen; 3: 6-d 100\% oxygen; 4: 10-d PRN oxygen; 5: 10-d 100\% oxygen. Minimal nonspecific bands were noted (not shown). $B$ : Quantification of p53 Western immunoblot. Both bands of the p53 doublet were used for quantification. *The 10-d PRN oxygen and 10-d 100\% oxygen animals are statistically different, $p$ $=0.02$. Open column is 140-d gestational control animals, shaded columns are PRN oxygen animals, and solid columns are $100 \%$ oxygen-treated animals. (Data are means \pm standard error of the mean. $n=3-4$ at each study condition.) 

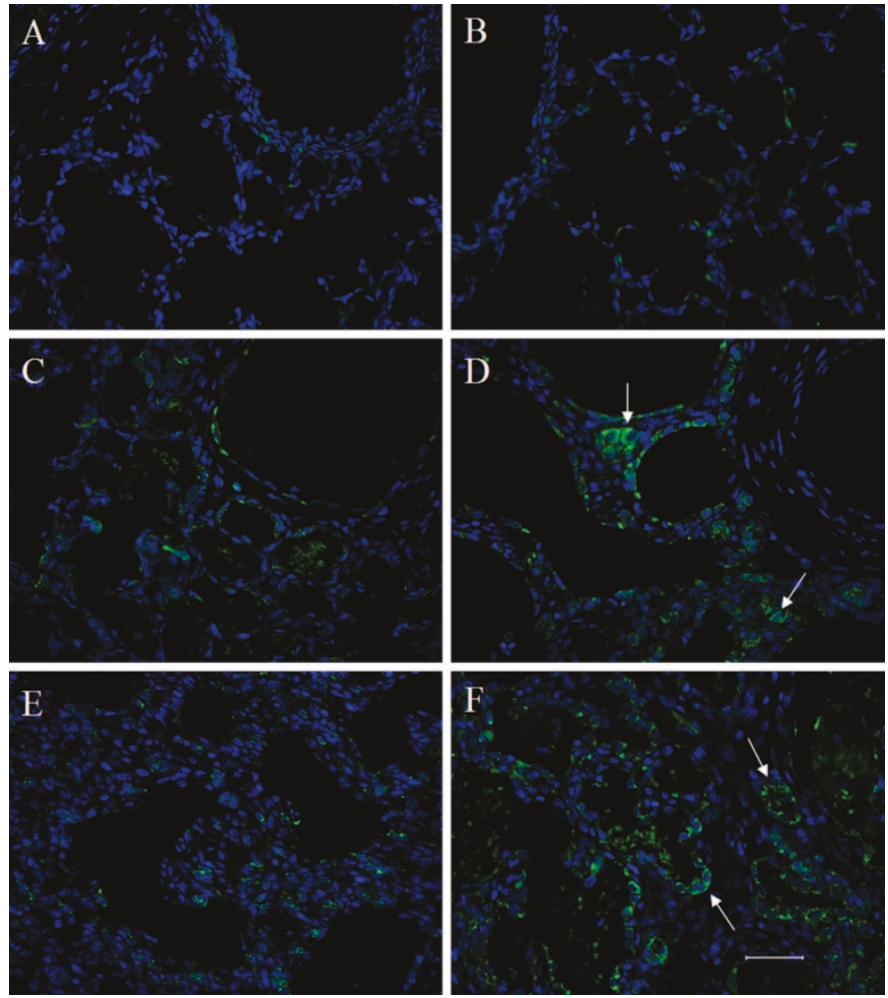

Figure 3. Increased 8-oxoG in hyperoxic lung. Oxidized guanine in damaged DNA was detected by a fluorescent 8 -oxoG (FITC conjugated) binding peptide in gestational controls, PRN oxygen animals, and animals exposed to $100 \%$ oxygen. Sections were counterstained with DAPI (blue) to detect all cell nuclei. Gestational controls ( $A$ : $146 \mathrm{~d}$ and $B: 160 \mathrm{~d}$ ) have little 8-oxoG signal in the parenchyma. Autofluorescent red blood cells are present in both samples. The 6-d PRN oxygen animals $(C)$ had minimal 8-oxoG signal. Fluorescent material in airspaces is probably autofluorescent red blood cells. The 6-d 100\% oxygen animals (D) had areas with increased 8-oxoG in both epithelial cells and mesenchymal cells (arrows). The 8oxoG signal appeared perinuclear. The 10 -d PRN oxygen animals $(E)$ had scattered cells with detectable 8-oxoG. The 10 -d $100 \%$ oxygen animals $(F)$ had areas with substantially increased perinuclear 8-oxoG signal that involved both distal epithelial and mesenchymal cells (arrows). Representative sections from two to four animals from each group. Detection of 8-oxoG was done simultaneously in all samples. Bar $=50 \mu \mathrm{M}$.

cells. The 8-oxoG signal was almost entirely perinuclear. Similarly, the 10-d PRN oxygen lung had scattered cells with 8-oxoG (Fig. 3E), but substantially increased perinuclear signal was noted in the 10-d 100\% oxygen animals, particularly in the distal epithelial cells (Fig. 3F, arrows). The perinuclear localization of 8-oxoG in the hyperoxic animals suggested that it was in mitochondrial DNA. This was confirmed by dual fluorescent microscopy for 8 -oxoG and the mitochondrial marker cytochrome oxidase subunit 1 (Fig. 4). Confocal microscopy of 140-d 10-d 100\% oxygen lung confirmed the perinuclear localization of 8-oxoG signal (Fig. 4A). Similarly, anticytochrome oxidase subunit 1 antibody binding was also perinuclear (Fig. 4B). Combining the confocal images (Fig. 4C) showed extensive perinuclear yellow signal of the hyperoxic lung, suggesting oxidant damage in mitochondrial DNA.

Increased p21 immunostaining in hyperoxic lung. In addition to repressing VEGF expression, p53 can induce p21, which results in cell cycle arrest in G1 (38). Finding increased p21 in hyperoxic lung injury would support functional activation of p53 in hyperoxia. To determine whether p21 was
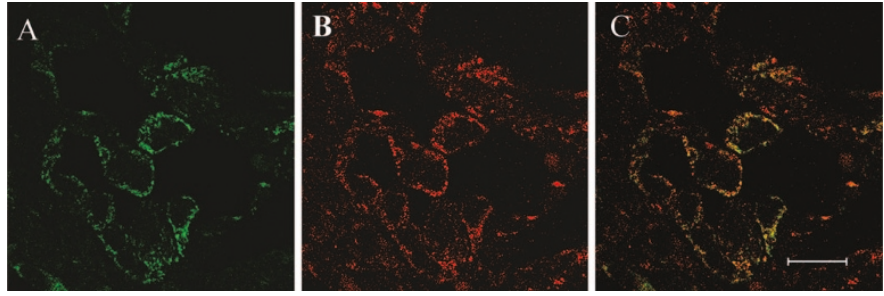

Figure 4. Dual immunofluorescent confocal microscopy of 8-oxoG (FITC) and mitochondrial-specific anti-cytochrome oxidase subunit 1 antibody (Texas red). High magnification $(100 \times)$ of lung from 10-d $100 \%$ oxygen-exposed animal shows perinuclear location of 8 -oxoG $(A)$. In the same section, the mitochondrial marker is also perinuclear $(B)$. Combined image shows concordance in location of 8 -oxoG and anti-cytochrome oxidase subunit 1 , as indicated by yellow color. Representative images from two animals from each group. $\mathrm{Bar}=20 \mu \mathrm{M}$.

expressed, we identified the protein by immunostaining in 140 d gestational controls and in 6- and 10-d PRN oxygen and hyperoxic animals. Gestational controls had occasional cells with p21-positive nuclei (not shown). The 6-d PRN oxygen animals had some p21-positive nuclei (Fig. 5A), which appeared to decrease in the 10-d PRN oxygen animals (Fig. 5C). However, both 6- and 10-d hyperoxic animals had substantial nuclear staining for p21 compared with the PRN animals (Fig. 5B and D). Similar to p53, p21-positive nuclei were found in both distal airspace epithelial cells and interairspace mesenchymal cells, although it appeared more common in epithelial cells. The control antibody gave minimal staining (insert, Fig. 5D). These data are consistent with an increase in functional p53 in hyperoxic fetal lung.

Decreased VEGF in hyperoxic lung. Because p53 may regulate the expression of VEGF, we examined message for VEGF in lungs from PRN and hyperoxic animals (Fig. 6). By RPA, VEGF mRNA was not different between the 6-d PRN oxygen animals and the 6-d 100\% oxygen animals. However, by $10 \mathrm{~d}$ of $100 \%$ oxygen, VEGF mRNA levels were signifi-

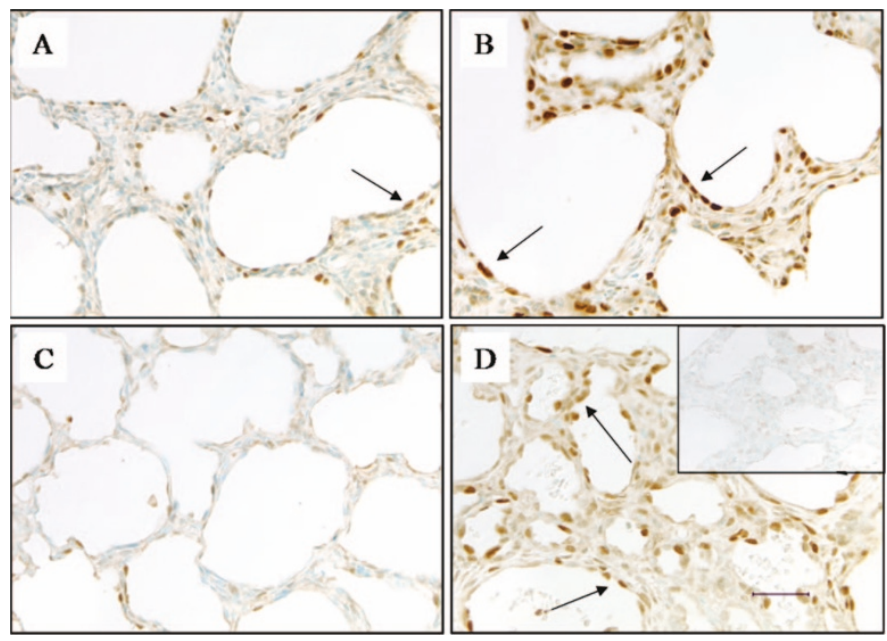

Figure 5. Immunohistochemistry for p21 in hyperoxic fetal baboon lung. $A$ : 6-d PRN oxygen animal had scattered cells with nuclear p21 (brown staining, arrow). B: 6-d 100\% oxygen animal had increased cells with p21 (arrow). C: 10-d PRN animal had minimal p21. D: 10-d 100\% oxygen animal had many p21-positive nuclei in both epithelial (arrows) and mesenchymal cells. The control antibody gave minimal staining (insert). Representative images from three animals from each group. Bar $=50 \mu \mathrm{M}$. 
A.

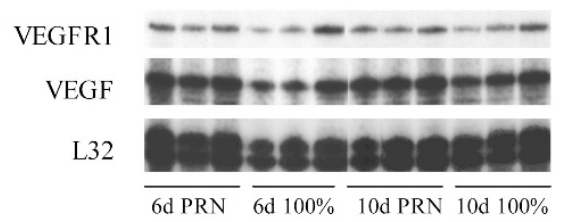

B.

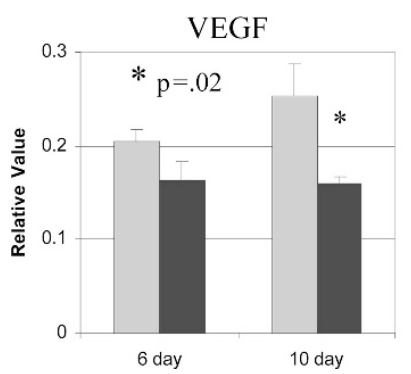

C.

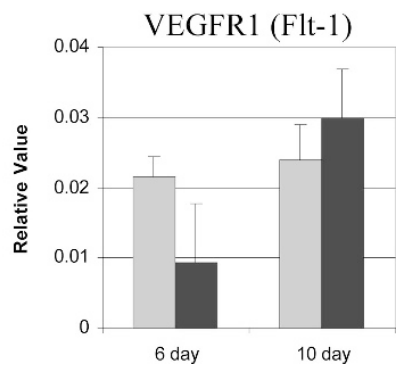

Figure 6. Expression of VEGF and VEGFR-1 in hyperoxic fetal baboon lung. A: Representative RPA in PRN oxygen and 100\% oxygen-exposed lung. Each lane represents a separate animal. B: Quantification of RPA analysis for VEGF. Shaded columns are PRN oxygen animals and solid columns are $100 \%$ oxygen animals at 6 and $10 \mathrm{~d}$. Data are expressed relative to L32. Both bands of L32 were used for quantification. $C$ : Quantification of VEGFR-1. *The hyperoxic animals are statistically different from the PRN oxygen animals at that time point, $p=0.02$. (Data are mean \pm standard error of the mean; $n=4-6$ at each study condition.)

cantly decreased compared with the 10d PRN animals (Fig. $6 \mathrm{~B} ; p=0.02$ ). Because decreased VEGF signaling may increase oxidant stress, we examined the message for the VEGF receptor VEGFR-1 (Flt-1). There were no differences in VEGFR-1 expression in the hyperoxic animals compared with the controls (Fig. 6C). Alternative splicing of VEGF mRNA produces three main splice variants $\left(\mathrm{VEGF}_{121}, \mathrm{VEGF}_{165}\right.$, and $\left.\mathrm{VEGF}_{189}\right)$ that are translated into three isoforms with differing mitogenic effects on endothelial cells. We have documented previously in postnatal rabbit lung that hyperoxic lung injury alters the relative expression of these splice variants (37). In fetal baboon lungs exposed to hyperoxia, however, we found no changes in the molar ratios of the VEGF splice variants (Fig. 7).

Decreased VEGF mRNA in distal airspace epithelial cells in hyperoxic lung. In late fetal lung from baboon and other species, VEGF mRNA is found mainly in distal epithelial cells that resemble type II cells $(5,12,13)$. In situ hybridization for VEGF in 10-d PRN oxygen animals (Fig. 8A and B) found a distribution of VEGF mRNA that was concentrated in individual cells in the distal epithelium. The mesenchyme of the interairspace septa also had signal above background, but minimal grains were noted in conducting airway epithelium or large blood vessel endothelial cells. These findings are similar to previously reported data on cell-specific VEGF expression in normal fetal baboon lung (5). In the 10-d 100\% oxygen animals, however, there was a marked decrease in the expression of VEGF by distal epithelial cells (Fig. 8C). The injury was heterogeneous, however, and some areas of lung had

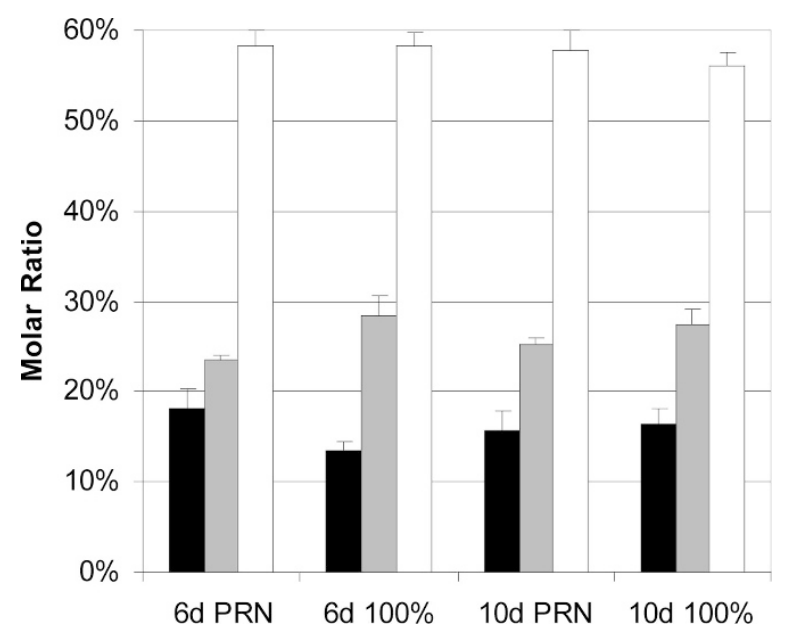

Figure 7. VEGF mRNA splice variant expression in hyperoxic fetal baboon lung. Molar ratios of $\mathrm{VEGF}_{189}$ (solid columns), $\mathrm{VEGF}_{165}$ (shaded columns), and VEGF $_{121}$ (open columns). Neither 6 nor $10 \mathrm{~d}$ of hyperoxia altered the molar ratios of VEGF mRNA splice variants. (Data are means \pm standard error of the mean; $n=4$ at each experimental condition.)

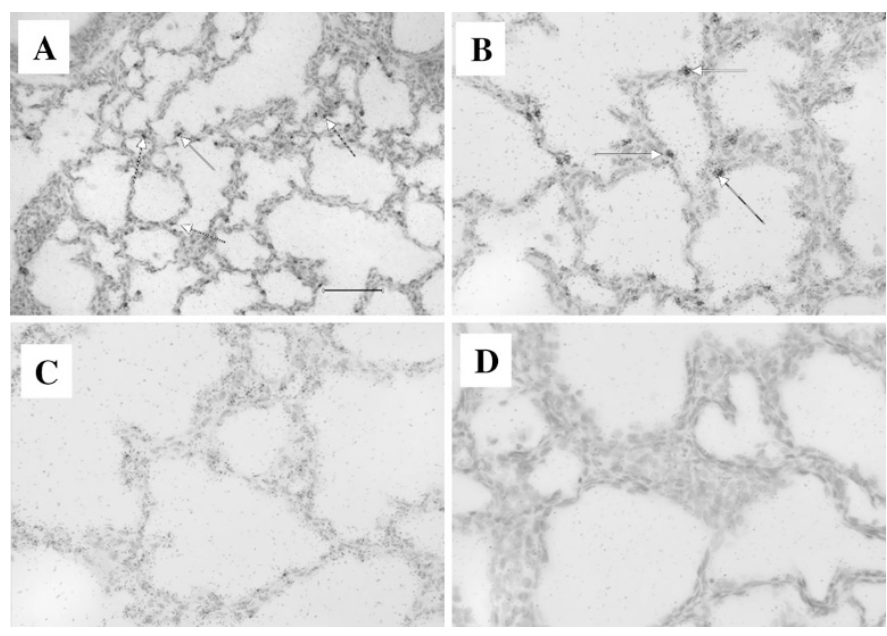

Figure 8. In situ hybridization for VEGF in 140-d gestation fetal baboon lung after $10 \mathrm{~d}$ of ventilation and exposure to PRN oxygen ( $A$ and $B$ ) or $100 \%$ oxygen $(C)$. The PRN animals had cells in the distal airspace epithelium that expressed high levels of VEGF message (black grains, arrows), but little signal in the conducting airspace epithelium or large vessel endothelium. In the 100\% oxygen animals, the distal airspace epithelium had decreased VEGF mRNA, but the mesenchymal cells continued to have VEGF message. The sense control had minimal signal $(D)$. All hybridizations were done simultaneously. Representative images from three animals from each group. Bar in $A=100$ $\mu \mathrm{M}$. For $B, C$ and $D$, bar $=50 \mu \mathrm{M}$.

VEGF expression that was similar to the PRN animals (not shown). The sense probe hybridization had minimal grains (Fig. 8D). These data suggest that hyperoxia and increased p53 are associated with decreased VEGF expression in fetal lung distal airspace epithelial cells.

\section{DISCUSSION}

Exposure to increased inspired oxygen is mechanistically linked to the development of chronic lung disease in premature infants. In developing lung, hyperoxia results in epithelial and endothelial cell loss, disordered proliferation, and other changes that may impede alveolar and microvascular develop- 
ment $(34,39,40)$. As shown in this and other studies, severe hyperoxia can decrease lung VEGF expression (6-8), which may disrupt microvascular development. VEGF may also be required for normal lung epithelial differentiation (41). The mechanism of decreased VEGF expression in hyperoxia is not known. Recent data suggest that the transcription factor p53 is increased in hyperoxic lung injury by phosphorylation of serine-15 to produce a stable isoform that is transcriptionally active (24). VEGF mRNA is decreased by p53 through mechanisms involving Sp-1 and HIF-1 $(25,27,29)$. We found increased p53 in distal lung epithelial cells of hyperoxic fetal baboon lung, which correlated with decreased VEGF expression in these cells. These data are consistent with a role for p53 in regulating VEGF. Further, we showed that hyperoxic fetal baboon lung had evidence of oxidant DNA injury in distal epithelial cells, identified by increased mitochondrial 8-oxoG. These data support oxidant DNA damage as a mechanism of increased $\mathrm{p} 53$ in this model.

In normal fetal lung development, VEGF message becomes abundant in distal epithelial cells that resemble type II cells $(12,13)$. The mechanism of epithelium-specific VEGF expression is not known but might be linked to normal type II cell proliferation and differentiation. Disrupted epithelial development, which is characteristic of BPD, is associated with decreased VEGF and an abnormal microvasculature $(3,5,42)$. Blockade of VEGF receptor-2 (VEGFR-2) resulted in impaired vascular development and alveolization (43), suggesting that normal vascularization is required for normal alveolization. VEGF is also a survival factor for endothelial cells and VEGF withdrawal results in endothelial cell death (44). We did not quantify endothelial cells in our study, but Coalson et al. (34) found decreased endothelial cells in 140-d gestation baboons after $11 \mathrm{~d}$ of $100 \%$ oxygen compared with animals treated with PRN oxygen.

Although several studies have shown decreased VEGF expression in hyperoxia $(6,7,15)$, the mechanism is not known. The present study supports a role for p53 in decreased VEGF mRNA. By forming a complex with the transcription factor Sp-1, p53 may inhibit VEGF expression by preventing Sp-1 binding to the VEGF promoter and abrogating Sp-1 induction of VEGF transcription $(25,27)$. Another mechanism of p53 effects on VEGF involves HIF-1. The VEGF promoter contains binding sites for HIF-1, a transcription factor that induces VEGF expression in hypoxic conditions $(17,45)$. p53 binds to HIF-1 and promotes proteosomal destruction of the HIF- $1 \alpha$ subunit (29). The role of HIF-1 in VEGF expression in fetal or postnatal lung is not known, but null mutants of a related factor, HIF-2, had decreased VEGF and disrupted lung development (41). Tumor cells with mutant p53 have high VEGF expression, and loss of p53 enhances HIF-1 induction of VEGF $(29,46)$. Increasing p53 by transfection or in temperaturesensitive mutants decreased VEGF expression by transcriptional mechanisms $(25,27,28,47)$. Decreased VEGF in hyperoxia is interesting because normal ROS signaling mechanisms can induce VEGF in vitro (48). Our findings of increased p53 and decreased VEGF mRNA in distal epithelial cells are consistent with p53 regulation of VEGF in hyperoxia.
The splice variant VEGF $_{121}$ was relatively more abundant in the PRN oxygen and hyperoxic baboons than $\mathrm{VEGF}_{165}$ or VEGF $_{189}$. This differs from late-gestation normal fetal rabbits but is similar to normal fetal mice $(14,37)$. Contrary to previous studies in hyperoxic neonatal rabbits (37), we found no major changes in the VEGF mRNA splice variant patterns in hyperoxic baboons compared with PRN oxygen animals. This might be related to species and age differences in the studies (fetal baboon versus neonatal rabbit). Although VEGF isoforms differ in their extracellular matrix binding and mitogenic potential, the significance of changes in their relative expression is unknown.

The mechanism of increased p53 in hyperoxic baboon lung may be related to oxidant-induced DNA damage. ROS can oxidize DNA, particularly at guanine residues, resulting in DNA strand breaks. We documented oxidant DNA damage in $100 \%$ oxygen-treated animals by detecting the DNA oxidation product 8-oxoG. Increased lung 8-oxoG was recently found in neonatal rats exposed to hyperoxia (19). Using confocal microscopy and an antibody to the mitochondrial protein cytochrome oxidase subunit 1 , we localized 8 -oxoG to mitochondria. Little 8-oxoG was detected in nuclei. Recent studies show that mitochondrial DNA is three times more sensitive to oxidant injury than nuclear DNA (21), possibly related to mitochondria as a primary source of ROS. Mitochondrial DNA also lacks chromatin, which may protect DNA from oxidant injury. Our finding of mitochondrial rather than nuclear DNA damage may reflect greater oxidant injury to mitochondrial DNA or a limited sensitivity of the 8-oxoG detection methods. Documenting nuclear DNA damage by other techniques, such as comet assays, is not feasible with the lung samples obtained from these animals. In adult mice treated with $100 \%$ oxygen, we found increased mitochondrial 8-oxoG that correlated with nuclear DNA strand breaks, measured by comet assays (20). However, the current studies cannot prove oxidant damage to nuclear DNA.

As shown by our data, p53 has relatively low expression in normal developing lung. Although p53 null mutant mice have no apparent pulmonary defects, p53 has been linked to the differentiation of the distal airspace epithelium (30). In adult mice, hyperoxia induces alveolar epithelial p53 expression (24). In hyperoxic injury, p53 accumulates by posttranscriptional mechanisms, including phosphorylation of serine-15, which increases stability of the protein (24). In the present study, we found an increase in total p53, which likely represents an increase in the serine- 15 phosphorylated species.

A significant role of p53 in oxidant lung injury may be to allow DNA repair. Cells with increased p53 transiently arrest in G1 to permit DNA repair or to enter the apoptotic pathway if the DNA damage is severe. The growth-inhibitory effects of p53 are mediated by induction of p21, a cyclin-dependent kinase inhibitor (49). In adult rodents, lung p21 is also induced by hyperoxia, although the mechanisms are both p53 dependent and independent (38). Because p53 can regulate cell cycle progression, apoptosis, Sp-1 binding, and HIF-1 stability, it may be central to multiple lung cell responses to hyperoxia.

The present study showed that several cell types had 8-oxoG and expressed p53 in the hyperoxic fetal lung, including both 
epithelial and mesenchymal cells. Increased epithelial p53 may decrease VEGF expression in those cells. Although our data cannot identify the mesenchymal cells that express these factors, both p53 and p21 are increased in endothelial cells undergoing apoptosis in vitro $(33,50)$. LPS-treated endothelial cells have increased p53 expression and become apoptotic, which can be prevented by pretreatment with VEGF (32).

This study has certain important limitations. The model of premature baboons closely mimics the clinical scenario of hyperoxic injury to developing, ventilated human lungs. The data are correlative and cannot define precise mechanisms, but they are important to support or refute hypotheses directly relevant to a complex lung disease. The model is very useful in documenting the effects of clinically relevant interventions, such as hyperoxia, on complex processes, such as fetal lung vascular and epithelial development. As groups, the PRN oxygen and hyperoxic animals differed somewhat in their ventilator settings by $10 \mathrm{~d}$, with the hyperoxic animals requiring a higher mean airway pressure to maintain normal arterial blood gases (36). The contribution of this difference to our findings is not known, but our data are consistent with hyperoxic induction of DNA damage, p53, and decreased VEGF seen in nonventilated models $(6,20,24)$. We did not examine changes in vascular development coincident with alterations in VEGF, p53, or p21. However, previous investigators have documented decreased endothelial cells in this model (34). Hyperoxic lung injury and BPD are somewhat heterogeneous and some areas of the lung in our studies appear relatively normal. However, quantifying p53 protein and VEGF mRNA confirmed the immunohistochemical and in situ hybridization studies.

In summary, exposure to $100 \%$ oxygen resulted in oxidant DNA damage, increased p53, and decreased VEGF expression in fetal baboon lungs. Increased epithelial p53 expression is a potential mechanism of decreased VEGF expression. Oxidant DNA damage, identified by increased 8-oxoG, may be a mechanism of increased p53 in hyperoxic injury. Other potential roles for p53 in hyperoxic injury may be as a mediator of cell cycle arrest and endothelial cell death. These responses to hyperoxia are likely to have deleterious effects on lung development.

Acknowledgments. The authors thank Colleen Shea for excellent technical assistance.

\section{REFERENCES}

1. Crapo JD 1986 Morphologic changes in pulmonary oxygen toxicity. Annu Rev Physiol 48:721-731

2. Coalson J 2000 Pathology of chronic lung disease in early infancy. In: Bland R, Coalson JJ (eds) Chronic Lung Disease in Early Infancy. Marcel Dekker, New York, pp $85-124$

3. Bhatt AJ, Pryhuber GS, Huyck H, Watkins RH, Metlay LA, Maniscalco WM 2001 Disrupted pulmonary vasculature and decreased vascular endothelial growth factor, Flt-1, and TIE-2 in human infants dying with bronchopulmonary dysplasia. Am J Respir Crit Care Med 164:1971-1980

4. Coalson JJ, Winter VT, Siler-Khodr T, Yoder BA 1999 Neonatal chronic lung disease in extremely immature baboons. Am J Respir Crit Care Med 160:1333-1346

5. Maniscalco WM, Watkins RH, Pryhuber GS, Bhatt A, Shea C, Huyck H 2002 Angiogenic factors and alveolar vasculature: development and alterations by injury in very premature baboons. Am J Physiol Lung Cell Mol Physiol 282:L811-L823

6. Maniscalco WM, Watkins RH, D'Angio CT, Ryan RM 1997 Hyperoxic injury decreases alveolar epithelial cell expression of vascular endothelial growth factor (VEGF) in neonatal rabbit lung. Am J Respir Cell Mol Biol. 16:557-567
7. Perkett EA, Klekamp JG 1998 Vascular endothelial growth factor expression is decreased in rat lung following exposure to 24 or 48 hours of hyperoxia: implications for endothelial cell survival. Chest 114:52S-53S

8. Hosford GE, Olson DM 2003 Effects of hyperoxia on VEGF, its receptors, and HIF-2alpha in the newborn rat lung. Am J Physiol Lung Cell Mol Physiol 285:L161L168

9. Thickett DR, Armstrong L, Millar AB 2002 A role for vascular endothelial growth factor in acute and resolving lung injury. Am J Respir Crit Care Med 166:1332-1337

10. Tsokos M, Pufe T, Paulsen F, Anders S, Mentlein R 2003 Pulmonary expression of vascular endothelial growth factor in sepsis. Arch Pathol Lab Med 127:331-335

11. Carmeliet P, Ferreira V, Breier G, Pollefeyt S, Kieckens L, Gertsenstein M, Fahrig M, Vandenhoeck A, Harpal K, Eberhardt C, Declercq C, Pawling J, Moons L, Collen D, Risau W, Nagy A 1996 Abnormal blood vessel development and lethality in embryos lacking a single VEGF allele. Nature 380:435-439

12. Bhatt AJ, Amin SB, Chess PR, Watkins RH, Maniscalco WM 2000 Expression of vascular endothelial growth factor and Flk-1 in developing and glucocorticoid-treated mouse lung. Pediatr Res 47:606-613

13. Zeng X, Wert SE, Federici R, Peters KG, Whitsett JA 1998 VEGF enhances pulmonary vasculogenesis and disrupts lung morphogenesis in vivo. Dev Dyn 211:215-227

14. Galambos C, Ng YS, Ali A, Noguchi A, Lovejoy S, D'Amore PA, DeMello DE 2002 Defective pulmonary development in the absence of heparin-binding vascular endothelial growth factor isoforms. Am J Respir Cell Mol Biol 27:194-203

15. Alon T, Hemo I, Itin A, Pe'er J, Stone J, Keshet E 1995 Vascular endothelial growth factor acts as a survival factor for newly formed retinal vessels and has implications for retinopathy of prematurity. Nature Med. 1:1024-1028

16. Benjamin LE, Keshet E 1997 Conditional switching of vascular endothelial growth factor (VEGF) expression in tumors: induction of endothelial cell shedding and regression of hemangioblastoma-like vessels by VEGF withdrawal. Proc Natl Acad Sci U S A 94:8761-8766

17. Forsythe JA, Jiang BH, Iyer NV, Agani F, Leung SW, Koos RD, Semenza GL 1996 Activation of vascular endothelial growth factor gene transcription by hypoxiainducible factor 1. Mol Cell Biol. 16:4604-4613

18. Tuder RM, Zhen L, Cho CY, Taraseviciene-Stewart L, Kasahara Y, Salvemini D, Voelkel NF, Flores SC 2003 Oxidative stress and apoptosis interact and cause emphysema due to vascular endothelial growth factor receptor blockade. Am J Respir Cell Mol Biol 29:88-97

19. Auten RL, Whorton MH, Nicholas Mason S 2002 Blocking neutrophil influx reduces DNA damage in hyperoxia-exposed newborn rat lung. Am J Respir Cell Mol Biol 26:391-397

20. Roper JM, Mazzatti DJ, Watkins RH, Maniscalco WM, Keng PC, O’Reilly MA 2004 In vivo exposure to hyperoxia induces DNA damage in a population of alveolar type II epithelial cells. Am J Physiol Lung Cell Mol Physiol 286:L1045-L1054

21. Bohr VA, Stevnsner T, de Souza-Pinto NC 2002 Mitochondrial DNA repair of oxidative damage in mammalian cells. Gene 286:127-134

22. Abid MR, Tsai JC, Spokes KC, Deshpande SS, Irani K, Aird WC 2001 Vascular endothelial growth factor induces manganese-superoxide dismutase expression in endothelial cells by a Rac1-regulated NADPH oxidase-dependent mechanism. FASEB J 15:2548-2550

23. Kroll J, Waltenberger J 1998 VEGF-A induces expression of eNOS and iNOS in endothelial cells via VEGF receptor-2 (KDR). Biochem Biophys Res Commun 252:743-746

24. O'Reilly MA, Staversky RJ, Stripp BR, Finkelstein JN 1998 Exposure to hyperoxia induces p53 expression in mouse lung epithelium. Am J Respir Cell Mol Biol 18:43-50

25. Pal S, Datta K, Mukhopadhyay D 2001 Central role of p53 on regulation of vascular permeability factor/vascular endothelial growth factor (VPF/VEGF) expression in mammary carcinoma. Cancer Res 61:6952-6957

26. Riccioni T, Cirielli C, Wang X, Passaniti A, Capogrossi MC 1998; Adenovirusmediated wild-type p53 overexpression inhibits endothelial cell differentiation in vitro and angiogenesis in vivo. Gene Ther 5:747-754

27. Zhang L, Yu D, Hu M, Xiong S, Lang A, Ellis LM, Pollock RE 2000 Wild-type p53 suppresses angiogenesis in human leiomyosarcoma and synovial sarcoma by transcriptional suppression of vascular endothelial growth factor expression. Cancer Res 60:3655-3661

28. Fujisawa T, Watanabe J, Kamata Y, Hamano M, Hata H, Kuramoto H 2003 Effect of p53 gene transfection on vascular endothelial growth factor expression in endometrial cancer cells. Exp Mol Pathol 74:276-281

29. Ravi R, Mookerjee B, Bhujwalla ZM, Sutter CH, Artemov D, Zeng Q, Dillehay LE, Madan A, Semenza GL, Bedi A 2000 Regulation of tumor angiogenesis by p53induced degradation of hypoxia-inducible factor 1alpha. Genes Dev 14:34-44

30. Tebar M, Boex JJ, Ten Have-Opbroek AA 2001 Functional overexpression of wild-type p53 correlates with alveolar cell differentiation in the developing human lung. Anat Rec 263:25-34

31. Rancourt RC, Keng PC, Helt CE, O'Reilly MA 2001 The role of p21(CIP1/WAF1) in growth of epithelial cells exposed to hyperoxia. Am J Physiol Lung Cell Mol Physio 280:L617-626

32. Munshi N, Fernandis AZ, Cherla RP, Park IW, Ganju RK 2002 Lipopolysaccharideinduced apoptosis of endothelial cells and its inhibition by vascular endothelial growth factor. J Immunol 168:5860-5866

33. Stromblad S, Becker JC, Yebra M, Brooks PC, Cheresh DA 1996 Suppression of p53 activity and $\mathrm{p} 21^{\mathrm{WAF} 1 / \mathrm{CIP} 1}$ expression by vascular cell integrin alphaVbeta3 during angiogenesis. J Clin Invest 98:426-433

34. Coalson JJ, Kuehl TJ, Prihoda TJ, deLemos RA 1988 Diffuse alveolar damage in the evolution of bronchopulmonary dysplasia in the baboon. Pediatr Res 24:357-366 
35. Coalson JJ, Kuehl TJ, Escobedo MB, Hilliard JL, Smith F, Meredith K, Null DM Jr., Walsh W, Johnson D, Robotham JL 1982 A baboon model of bronchopulmonary dysplasia. II. Pathologic features. Exp Mol Pathol 37:335-350

36. Delemos RA, Coalson JJ, Gerstmann DR, Kuehl TJ, Null Jr DM 1987 Oxygen toxicity in the premature baboon with hyaline membrane disease. Am Rev Respir Dis 136:677-682

37. Watkins RH, D’Angio CT, Ryan RM, Patel A, Maniscalco WM 1999 Differential expression of VEGF mRNA splice variants in newborn and adult hyperoxic lung injury. Am J Physiol 276:L858-L867

38. O'Reilly MA, Staversky RJ, Watkins RH, Maniscalco WM 1998 Accumulation of p21 (Cipi/WAF1) during hyperoxic lung injury in mice. Am J Respir Cell Mol Biol 19:777-785

39. Bruce MC, Honaker CE 1998 Transcriptional regulation of tropoelastin expression in rat lung fibroblasts: changes with age and hyperoxia. Am J Physiol 274:L940-L950

40. Warner BB, Stuart LA, Papes RA, Wispe JR 1998 Functional and pathological effect of prolonged hyperoxia in neonatal mice. Am J Physiol 275:L110-L117

41. Compernolle V, Brusselmans K, Acker T, Hoet P, Tjwa M, Beck H, Plaisance S, Dor Y, Keshet E, Lupu F, Nemery B, Dewerchin M, Van Veldhoven P, Plate K, Moon L, Collen D, Carmeliet P 2002 Loss of HIF-2alpha and inhibition of VEGF impai fetal lung maturation, whereas treatment with VEGF prevents fatal respiratory distress in premature mice. Nat Med 8:702-710

42. Lassus P, Turanlahti M, Heikkila P, Andersson LC, Nupponen I, Sarnesto A, Andersson S 2001 Pulmonary vascular endothelial growth factor and Flt-1 in fetuses, in acute and chronic lung disease, and in persistent pulmonary hypertension of the newborn. Am J Respir Crit Care Med 164:1981-1987

43. Jakkula M, Le Cras TD, Gebb S, Hirth KP, Tuder RM, Voelkel NF, Abman SH 2000 Inhibition of angiogenesis decreases alveolarization in the developing rat lung. Am J Physiol Lung Cell Mol Physiol 279:L600-L607
44. Gerber HP, McMurtrey A, Kowalski J, Yan M, Keyt BA, Dixit V, Ferrara N 1998 Vascular endothelial growth factor regulates endothelial cell survival through the phosphatidylinositol 3'-kinase/Akt signal transduction pathway. Requirement for Flk-1/KDR activation. J Biol Chem 273:3033630343

45. Carmeliet P, Dor Y, Herbert JM, Fukumura D, Brusselmans K, Dewerchin M, Neeman M, Bono F, Abramovitch R, Maxwell P, Koch CJ, Ratcliffe P, Moons L, Jain RK, Collen D, Keshert E, Keshet E 1998 Role of HIF-1alpha in hypoxiamediated apoptosis, cell proliferation and tumour angiogenesis. Nature 394: 485-490

46. Fontanini G, Boldrini L, Vignati S, Chine S, Basolo F, Silvestri V, Lucchi M, Mussi A, Angeletti CA, Bevilacqua G $1998 \mathrm{Bcl} 2$ and p53 regulate vascular endothelial growth factor (VEGF)-mediated angiogenesis in non-small cell lung carcinoma. Eur J Cancer 34:718-723

47. Tai YT, Podar K, Gupta D, Lin B, Young G, Akiyama M, Anderson KC 2002 CD40 activation induces p53-dependent vascular endothelial growth factor secretion in human multiple myeloma cells. Blood 99:1419-1427

48. Kosmidou I, Xagorari A, Roussos C, Papapetropoulos A 2001 Reactive oxygen species stimulate VEGF production from $\mathrm{C}(2) \mathrm{C}(12)$ skeletal myotubes through a PI3K/Akt pathway. Am J Physiol Lung Cell Mol Physiol 280: L585-L592

49. Dulic V, Kaufmann WK, Wilson SJ, Tlsty TD, Lees E, Harper JW, Elledge SJ, Reed SI 1994 p53-dependent inhibition of cyclin-dependent kinase activities in human fibroblasts during radiation-induced G1 arrest. Cell 76:1013-1023

50. Teruyama K, Abe M, Nakano T, Iwasaka-Yagi C, Takahashi S, Yamada S, Sato Y 2001 Role of transcription factor Ets-1 in the apoptosis of human vascular endothelial cells. J Cell Physiol 188:243-252 